\title{
Clinical picture of lupus nephritis in patients with systemic lupus erythematosus (SLE): Results of a large survey
}

\author{
Seyedeh Tahereh Faezi, Mahdieh Hosseini Almodarresi, Pedram Paragomi*, Farhad Gharibdoost, Maasoumeh \\ Akhlaghi, Ahamadreza Jamshidi, Nahid Shafaie and Mahmood Akbarian \\ Rheumatology Research Center, Tehran University of Medical Sciences, Iran
}

\begin{abstract}
Systemic lupus erythematosus (SLE) is a chronic multisystem disorder. Lupus nephritis (LN) is a common serious complication of SLE. LN needs prolonged care and complex therapeutic modalities. This study assessed the characteristics of Persian SLE patients with LN (LN subgroup) and an SLE subpopulation without LN (non-LN subgroup). Furthermore, the association of LN with extrarenal manifestations of SLE was studied. This study assessed 2355 SLE patients from the electronic database of the Rheumatology Research Center (RRC), Tehran University of Medical Sciences (TUMS). The clinical and laboratory data of enrolled patients was retrieved. The chi-square test was used to compare extrarenal manifestations of the $\mathrm{LN}$ and non-LN subgroups. Odds ratios (OR) were used to present the strength of associations. The LN subgroup included 1604 cases $(68.1 \%)$ with a mean age at SLE onset of $24.6 \pm 12.5$ years and a female-to-male ratio of 8.7/1. Class IV nephritis was the most common type of LN (53.1\%). The comparison of extrarenal manifestations revealed statistically significant differences between LN and non-LN subgroups. Major organ involvement including cardiopulmonary, hematologic, musculoskeletal and neuropsychiatric features was significantly more common in LN patients. On the contrary, discoid rash was significantly more common in the non-LN subgroup. This study revealed that LN is positively associated with musculoskeletal, mucocutaneous, and neuropsychiatric features of SLE.
\end{abstract}

Keywords: kidney, nephritis, systemic lupus erythematosus.

\section{Introduction}

Systemic lupus erythematosus (SLE) is a chronic and recurrent autoimmune disease with diverse clinical manifestations and a highly variable prognosis [1]. The underlying pathogenesis and causative factors of SLE are yet to be elucidated. A combination of genetic and environmental factors have been implicated in disease susceptibility [2, 3].

An overall incidence rate of 1.4 to 21.9 and a prevalence rate of 7.4 to 159.4 per 100,000 have been reported for SLE [4]. Marked disparities in prevalence rates of SLE have been noted across different ethnicities [4]. The reported prevalence of SLE in the Persian population is 40 per 100,000 [5]. There is significant patient-to-patient variability in the clinical manifestations and severity of SLE [6]. Populationspecific risk factors play key roles in the development of SLE clinical variants based on ethnicity and geography [2].

Renal involvement is common in SLE. It is estimated that up to $90 \%$ of SLE patients have pathologic evidence of renal involvement on biopsy, while only $50 \%$ of cases develop clinically-significant nephritis [7]. A study of lupus in a Spanish population reported a $30.5 \%$ prevalence rate for $\mathrm{LN}$. The response rate in this study was $68.3 \%$, and $10.35 \%$ of $\mathrm{LN}$ cases developed end-stage renal disease [8]. A study by Maroz et al. revealed that $10-15 \%$ of the progression of LN to ESRD occurred within 15 years of diagnosis [9]. Another survey in a multi-ethnic population reported a prevalence rate of $32.9 \%$ for LN among SLE patients [10]. It is noteworthy that this survey emphasized the differential prevalence of $\mathrm{LN}$ among various ethnic subpopulations [10].

LN incidence and prevalence rates depend on the selected population and the SLE diagnostic criteria [7, 11]. Furthermore, according to previous large surveys, LN tends to develop at a younger age [12]. The cumulative incidence of $\mathrm{LN}$ is relatively higher in Asian, African, and Hispanic populations in comparison with Caucasians [4, 6, 11, 13, 14].

A number of clinical features have been reported by previous studies as risk factors for the development of LN, such as malar rash, pericarditis, arterial

* Corresponding Author: Pedram Paragomi, Email: pedram.paragomi@ gmail.com, Tel/Fax: +98 2188026956

Received: 10 December 2016; Accepted: 05 February 2017 
hypertention, anemia, low levels of serum complements, and raised anti-dsDNA [8, 9, 10]. Risk factors for progressive LN are male gender, African lineage, Hispanic ethinicity, age less than 24 years, hypertension, anemia, serum antiphospholipid antibodies, and non-compliant patients [7].

The current study assessed the clinical, laboratory, and therapeutic aspects of LN in a large sample of SLE patients and compared these characteristics with those of SLE patients without LN.

\section{Materials and Methods}

In this cross-sectional study, the electronic database of the Rheumatology Research Center (RRC) of Tehran University of Medical Sciences (TUMS) was used, which had the registered and updated demographic features, clinical and paraclinical manifestations of 2355 SLE patients between 1976 and 2011. The electronic database, launched in 2007, contains the data of ongoing referrals of SLE patients to this academic center since 1987. Patients diagnosed with SLE based on the American College of Rheumatology (ACR) criteria for classification of SLE $[11,12]$ were enrolled. Patient follow-up visits were scheduled every 1-3 months depending on the severity of the disease.

Laboratory tests included complete blood count (CBC), urinanalysis, biochemistry, immunologic tests such as antinuclear antibody (ANA) (Antibodies Incorporated, Davis, USA), anti-double stranded DNA (dsDNA) (Biomatik, Wilmington, USA), and complement factors (C3 and C4) (Abcam, Cambridge, USA).

Renal involvement was defined by persistant abnormal proteinuria (>150 mg/24 hour) and/or the presence of cellular cast. Patients with dipstick-positive proteinuria were further evaluated by a 24-hour urine study. A renal biopsy was performed for patients with confirmed proteinuria $(>0.5 \mathrm{~g}$ in 24-hour urine samples) or active urinary sediment, and specimens were studied by light and immunofluorescence microscopy. All biopsies were examined by one pathologist at the academic hospital. The classification of lupus nephritis was based on the 1982 WHO classification criteria $[13,15]$. In the current study, a serum creatinine level between 1.5 and $3 \mathrm{mg} / \mathrm{dl}$ was considered as a mild to moderate rise, and $>3 \mathrm{mg} / \mathrm{dl}$ was considered as a severe creatinine rise. Hypertension was defined as a persistently elevated blood pressure above 140/90 $\mathrm{mmHg}$ and/or the use of antihypertensive treatment [14].

Clinical manifestations of SLE were compared in
LN and non-LN subgroups. Moreover, the LN cases in this study were compared with those in other large surveys. Histologic findings and treatments were compared between patients with creatinine rise and normal creatinine.

\section{Statistical analysis}

For LN patients' charactristics, either means with standard deviations (Mean \pm SD) or percentages were determined. Chi-square and Fisher's exact tests were used to examine statistical differences. Odds ratios (OR) and a 95\% confidence interval $(95 \% \mathrm{CI})$ were calculated to evaluate the effect size of the association. $\mathrm{T}$ test was used to compare mean ages. A p-value less than 0.05 was considered as statistically significant. This statistical analysis was performed by SPSS software version 20.0 (Chicago, IL).

\section{Results}

Among the 2355 SLE patients, nephritis developed in $1604(68.1 \%)$ cases. The LN subset was comprised of 1439 female $(89.7 \%)$ and 165 male patients $(10.3 \%)$. In $\mathrm{LN}$ cases, the female-to-male ratio was $8.7 / 1$. The mean age at disease onset was $24.6 \pm 12.5$ years, and the mean disease duration was $8.4 \pm 9.3$ years. Renal involvement was the first presenting manifestation in 58 patients (3.6\%, CI: 2.7-4.5).

Renal biopsies of 832 patients $(51.8 \%$ of patients with renal involvement) were available for analysis. Class IV was the most common type of LN (53.1\%) and class III was the second most common type of nephritis $(25.12 \%)$ (Table 1$)$.

A total of $1470(91.4 \%)$ patients had persistent proteinuria after confirmation of $\mathrm{LN}$ and while receiving treatment. In $24.3 \%$ of the patients, proteinuria was in the nephrotic range. Renal biopsies in this group identified class III nephritis in 134 cases and class IV in 256 cases. Cellular cast and hematuria were seen in $33.5 \%$ and $59.4 \%$ of patients, respectively. Furthermore, hypertension and edema were detected in $28.9 \%$ and $24 \%$ of the patients, respectively (Table 1).

Among the patients in this study, 22.8\% had a rise of creatinine in the course of their disease. Patients with raised creatinine levels had more common history of oral cytotoxic, methylprednisolone and cyclophosphamide pulse administration. Conversely, patients with a creatinine rise had a lower rate of antimalarial drug consumption and a lower prevalence of class II histological type (Table 2). 
Table 1. Renal manifestations of systemic lupus erythematosus (SLE)

\begin{tabular}{|c|c|c|}
\hline \multirow{2}{*}{ Presentation } & \multicolumn{2}{|c|}{ Frequency } \\
\hline & Number & $\%$ \\
\hline Proteinuria (150-500mg/day) & 434 & 27.0 \\
\hline Proteinuria (500-3000mg/day) & 645 & 40.2 \\
\hline Proteinuria (>3000mg/day) & 391 & 24.3 \\
\hline Cellular Cast & 538 & 33.5 \\
\hline Hematuria $(>5 \mathrm{RBC} / \mathrm{hpf}){ }^{\S}$ & 954 & 59.5 \\
\hline Raised Creatinine (Mild to moderate) ${ }^{\mathrm{I}}$ & 319 & 19.9 \\
\hline Raised Creatinine (Severe) $)^{\ddagger}$ & 47 & 2.9 \\
\hline Hypertension & 464 & 28.9 \\
\hline Edema & 386 & 24.0 \\
\hline Biopsy & 832 & 51.8 \\
\hline Class I & 3 & $0.4^{¥}$ \\
\hline Class II & 92 & $11.1^{¥}$ \\
\hline Class III & 209 & $25.1^{¥}$ \\
\hline Class IV & 442 & $53.1^{¥}$ \\
\hline Class V & 86 & $10.3^{¥}$ \\
\hline
\end{tabular}

₹: Percent from patients with biopsy, ${ }^{\S}$ : RBC: Red Blood Cell, hpf: high-power field, "I: Creatinine $<3 \mathrm{mg} / \mathrm{dL}$, $\neq$ : Creatinine $>3 \mathrm{mg} / \mathrm{dL}$

No difference in mean age at disease onset was observed in patients with or without LN (pvalue $=0.363$ )

A comparison of the initial SLE manifestations in $\mathrm{LN}$ and non-LN subgroups revealed that constitutional ( $\mathrm{p}$-value $<0.001, \mathrm{OR}=1.72$ ) and musculoskeletal ( $\mathrm{p}$ value $=0.031, \quad \mathrm{OR}=1.21$ ) manifestations were significantly more common in the LN subgroup.
Conversely, cutaneous manifestations ( $\mathrm{p}$-value $=0.005$, $\mathrm{OR}=0.76$ ) were significantly less common in the LN subgroup.

Throughout the course of the disease, LN patients had significantly higher rates of mucocutaneous $(82.1 \%$ vs. $78.1 \%$, p-value $=0.022)$, musculoskeletal $(86.9 \%$ vs. $75.8 \%, \quad$ p-value $<0.001)$, and neuropsychiatric $(27.3 \%$ vs. $25.6 \%$, p-value $<0.001)$ features. The detailed comparison of extrarenal manifestations during the course of SLE in LN and non-LN is tabulated in Table 3. Discoid rash was significantly less common in LN patients. Photosensitivity and pulmonary hypertension were less common in LN patients; however, the difference was not statistically significant. Other mucocutaneous, constitutional, musculoskeletal, neuropsychiatric, pulmonary, cardiac, and hematologic manifestations were more common in LN patients, and the differences among all these items were statistically-significant.

The prevalence of positive FANA, raised antidsDNA, and low complement levels were higher in the LN subset than the non-LN subgroup with statistically significant differences.

The administration of a moderate to high dose of steroids, oral cytotoxic, methylprednisolone, and cyclophosphamide pulse was more common among the LN subgroup, whereas antimalarial drugs were less frequently used in comparison with non-LN patients (Table 4).

The comparison of LN subsets in the current study and in different surveys revealed a discernible clinical picture of SLE among the studied population (Table 5).

Table 2. Comparison of raised creatinie between various subgroups of lupus nephritis, therapeutic regimens and in Anti ds-DNA positive cases

\begin{tabular}{lcccccc}
\hline Manifestations & \multicolumn{2}{c}{ Raised Cr } & \multicolumn{2}{c}{ Normal Cr } & \multirow{2}{*}{ P-value } & \multirow{2}{*}{ OR (95\% CI) } \\
& $\mathbf{N}$ & $\mathbf{\%}$ & $\mathbf{N}$ & $\mathbf{\%}$ & & \\
\hline Class 1 & 0 & 0 & 3 & 0.23 & 0.910 & $0.88(0.10-7.91)$ \\
Class 2 & 10 & 2.82 & 82 & 6.54 & 0.008 & $0.41(0.21-0.81)$ \\
Class 3 & 40 & 11.29 & 169 & 13.48 & 0.280 & $0.82(0.57-1.18)$ \\
Class 4 & 145 & 40.96 & 297 & 23.70 & 0.000 & $2.23(1.74-2.86)$ \\
Class 5 & 14 & 3.95 & 72 & 5.74 & 0.186 & $0.67(0.38-1.21)$ \\
\hline Antimalarial Drugs & 247 & 69.77 & 1028 & 82.04 & 0.000 & $0.55(0.42-0.72)$ \\
Pulse methylprednisolone & 121 & 34.18 & 190 & 15.16 & 0.000 & $3.02(2.31-3.95)$ \\
Oral Cytotoxics & 222 & 62.71 & 525 & 41.89 & 0.000 & $2.50(1.95-3.20)$ \\
Pulse Cyclophosphamide & 164 & 46.32 & 432 & 34.47 & 0.000 & $1.72(1.35-2.19)$ \\
\hline Anti-dsDNA positive & 250 & 70.62 & 905 & 72.22 & 0.931 & $1.01(0.77-1.32)$ \\
\hline
\end{tabular}

Cr: Creatinine, N: Number 
Lupus nephritis in patients with systemic lupus erythematosus

Table 3. Comparison of demographic features and clinical manifestations between lupus nephritis (LN) and non-LN subgroups

\begin{tabular}{|c|c|c|c|c|c|c|c|}
\hline \multirow{2}{*}{ Characteristics/Symptoms } & \multicolumn{2}{|c|}{$\mathbf{L N}$} & \multicolumn{2}{|c|}{ Non-LN } & \multicolumn{3}{|c|}{ Comparison } \\
\hline & $\mathbf{N}$ & $\%$ & $\mathbf{N}$ & $\%$ & Chi & p Value & OR $(95 \% \mathrm{CI})$ \\
\hline Female & 1439 & 89.5 & 677 & 89.9 & 0.072 & N.S & - \\
\hline Male & 165 & 10.3 & 74 & 9.8 & 0.109 & N.S & - \\
\hline Constitutional Manifestations & 1072 & 66.7 & 367 & 48.7 & 69.581 & $<0.001$ & $\begin{array}{c}2.12 \\
(1.78-2.52)\end{array}$ \\
\hline Musculoskeletal Manifestations & 1396 & 86.9 & 571 & 75.8 & 45.026 & $<0.001$ & $\begin{array}{c}2.14 \\
(1.71-2.67)\end{array}$ \\
\hline -Arthritis & 886 & 55.1 & 352 & 46.7 & 14.463 & $<0.001$ & $\begin{array}{c}1.41 \\
(1.18-1.67)\end{array}$ \\
\hline -Aseptic Necrosis & 96 & 6.0 & 16 & 2.1 & 16.804 & $<0.001$ & $\begin{array}{c}2.93 \\
(1.71-5.01)\end{array}$ \\
\hline -Myositis & 58 & 3.6 & 11 & 1.5 & 8.338 & 0.003 & $\begin{array}{c}2.53 \\
(1.32-4.85)\end{array}$ \\
\hline Mucocutaneous Manifestations & 1319 & 82.1 & 588 & 78.1 & 5.265 & 0.022 & $\begin{array}{c}1.28 \\
(1.03-1.59)\end{array}$ \\
\hline -Malar Rash & 1003 & 62.4 & 418 & 55.5 & 10.199 & 0.001 & $\begin{array}{c}1.34 \\
(1.12-1.60)\end{array}$ \\
\hline -Photosensitivity & 904 & 56.3 & 447 & 59.4 & 2.025 & N.S & - \\
\hline -Oral ulcer & 674 & 41.9 & 237 & 31.5 & 23.704 & $<0.001$ & $\begin{array}{c}1.58 \\
(1.31-1.89)\end{array}$ \\
\hline -Discoid Lesions & 189 & 11.8 & 149 & 19.8 & 26.920 & $<0.001$ & $\begin{array}{c}0.54 \\
(0.43-.068)\end{array}$ \\
\hline Neuropsychiatric Symptoms & 439 & 27.3 & 193 & 25.6 & 32.124 & $<0.001$ & $\begin{array}{c}1.74 \\
(1.44-2.11)\end{array}$ \\
\hline -Convulsions & 240 & 14.9 & 69 & 9.2 & 15.009 & $<0.001$ & $\begin{array}{c}1.74 \\
(1.31-2.31)\end{array}$ \\
\hline -Psychosis & 90 & 5.6 & 23 & 3.1 & 7.291 & 0.007 & $\begin{array}{c}1.89 \\
(1.18-3.01)\end{array}$ \\
\hline -Peripheral Neuropathy & 109 & 6.8 & 30 & 4.0 & 7.246 & 0.007 & $\begin{array}{c}1.76 \\
(1.16-2.66)\end{array}$ \\
\hline Pulmonary Manifestations & 403 & 25.1 & 102 & 13.5 & 40.541 & $<0.001$ & $\begin{array}{c}2.14 \\
(1.69-2.71)\end{array}$ \\
\hline -Pleuritis/ Pleurisy & 296 & 18.4 & 82 & 10.9 & 21.611 & $<0.001$ & $\begin{array}{c}1.85 \\
(1.42-2.40)\end{array}$ \\
\hline -Lupus Pneumonitis & 41 & 2.6 & 6 & 0.8 & 7.213 & 0.007 & $\begin{array}{c}3.27 \\
(1.38-7.73)\end{array}$ \\
\hline -Pulmonary hypertension & 3 & 0.2 & 2 & 0.3 & 0.755 & N.S & - \\
\hline Cardiac Manifestations & 324 & 20.2 & 74 & 9.8 & 39.058 & $<0.001$ & $\begin{array}{c}2.32 \\
(1.77-3.04)\end{array}$ \\
\hline -Pericarditis & 182 & 11.3 & 32 & 4.2 & 31.134 & $<0.001$ & $\begin{array}{c}2.88 \\
(1.96-4.24)\end{array}$ \\
\hline -Valvular lesions & 73 & 4.5 & 14 & 1.9 & 10.399 & 0.001 & $\begin{array}{c}2.51 \\
(1.41-4.49)\end{array}$ \\
\hline -Cardiomyopathy & 31 & 1.9 & 4 & 0.5 & 5.934 & 0.015 & $\begin{array}{c}3.69 \\
(1.30-10.50)\end{array}$ \\
\hline Leucopenia & 630 & 39.2 & 199 & 26.4 & 36.726 & $<0.001$ & $\begin{array}{c}1.80 \\
(1.49-2.18)\end{array}$ \\
\hline Hemolytic Anemia & 77 & 4.8 & 22 & 2.9 & 4.461 & 0.035 & $\begin{array}{c}1.68 \\
(1.03-2.71)\end{array}$ \\
\hline Thrombocytopenia & 314 & 19.5 & 108 & 14.3 & 9.431 & 0.002 & $\begin{array}{c}1.45 \\
(1.15-1.84)\end{array}$ \\
\hline Positive FANA & 1296 & 80.6 & 560 & 74.4 & 12.032 & $<0.001$ & $\begin{array}{c}1.45 \\
(1.18-1.78)\end{array}$ \\
\hline Raised Anti-dsDNA & 1212 & 75.4 & 464 & 61.6 & 48.475 & $<0.001$ & $\begin{array}{c}1.93 \\
(1.60-2.31)\end{array}$ \\
\hline Low C3 & 910 & 56.6 & 228 & 30.3 & 142.566 & $<0.001$ & $\begin{array}{c}3.02 \\
(2.51-3.63)\end{array}$ \\
\hline Low $\mathrm{C} 4$ & 907 & 56.4 & 258 & 34.3 & 100.893 & $<0.001$ & $\begin{array}{c}2.50 \\
(2.08-2.99)\end{array}$ \\
\hline
\end{tabular}

LN: Lupus nephritis, CI: Confidence intervals, N.S.: Non-significant 
Faezi et al.

Table 4. Comparison of therapeutic agents between lupus nephritis (LN) subgroup and non-LN subgroup

\begin{tabular}{|c|c|c|c|c|c|c|c|c|c|}
\hline \multirow{2}{*}{ Symptoms } & \multicolumn{3}{|c|}{$\mathbf{L N}$} & \multicolumn{3}{|c|}{ Non-LN } & \multicolumn{3}{|c|}{ Comparison } \\
\hline & $\mathbf{N}$ & $\%$ & CI & $\mathbf{N}$ & $\%$ & CI & Chi & p Value & OR $(95 \% \mathrm{CI})$ \\
\hline Oral Cytotoxics & 596 & 37.1 & $34.7-39.5$ & 163 & 21.6 & $18.7-24.5$ & 56.033 & $<0.001$ & $\begin{array}{c}2.14 \\
(1.75-2.62)\end{array}$ \\
\hline Antimalarial Drugs & 1275 & 79.3 & $77.3-81.3$ & 663 & 88.0 & $85.7-90.3$ & 26.475 & $<0.001$ & $\begin{array}{c}0.53 \\
(0.41-0.68)\end{array}$ \\
\hline Moderate Dose Steroids & 710 & 44.2 & $41.8-46.6$ & 196 & 26.0 & $22.9-29.1$ & 71.434 & $<0.001$ & $\begin{array}{c}2.26 \\
(1.87-2.73)\end{array}$ \\
\hline High Dose Steroids ${ }^{\ddagger}$ & 677 & 42.1 & $39.7-44.5$ & 142 & 18.9 & $16.1-21.7$ & 122.529 & $<0.001$ & $\begin{array}{c}3.14 \\
(2.55-3.87)\end{array}$ \\
\hline Pulse Methylprednisolone & 311 & 19.4 & $17.5-21.3$ & 29 & 3.9 & $2.5-5.3$ & 99.918 & $<0.001$ & $\begin{array}{c}6.00 \\
(4.06-8.88)\end{array}$ \\
\hline Pulse Cyclophosphamide & 747 & 46.5 & $44.1-48.9$ & 50 & 6.6 & $4.8-8.4$ & 363.942 & $<0.001$ & $\begin{array}{c}12.25 \\
(9.05-16.60)\end{array}$ \\
\hline Azathioprine & 142 & 8.8 & $7.4-10.2$ & 38 & 5.0 & $3.4-6.6$ & 10.453 & 0.001 & $\begin{array}{c}1.83 \\
(1.26-2.64)\end{array}$ \\
\hline Methotrexate & 57 & 3.5 & $2.6-4.4$ & 33 & 4.4 & $2.9-5.9$ & 0.976 & N.S. & - \\
\hline IVIG & 2 & 0.1 & $-0.1-0.3$ & 2 & 0.3 & $-0.1-0.7$ & 1.726 & N.S. & - \\
\hline Plasmapheresis & 15 & 0.9 & $0.4-1.4$ & 2 & 0.3 & $-0.1-0.7$ & 2.332 & N.S. & - \\
\hline Aspirin & 81 & 5.0 & $3.9-6.1$ & 26 & 3.5 & $2.2-4.8$ & 2.986 & N.S. & - \\
\hline Warfarin & 16 & 1.0 & $0.5-1.5$ & 14 & 1.9 & $0.9-2.9$ & 3.047 & N.S. & - \\
\hline ACEI & 89 & 5.5 & $4.4-6.6$ & 14 & 1.9 & $0.9-2.9$ & 16.627 & $<0.001$ & $\begin{array}{c}3.10 \\
(1.75-5.48)\end{array}$ \\
\hline
\end{tabular}

N: Number, N.S: Non-significant, ${ }^{¥}$ Moderate Dose Steroids: 16-30 mg, ${ }^{\ngtr}$ High Dose Steroids: 31-60 mg, IVIG: Intravenous immunoglobulin, ACEI: Angiotensin Converting Enzyme Inhibitor

Table 5. Comparison of demographic and clinical features of lupus nephritis in our study and some of the previous surveys

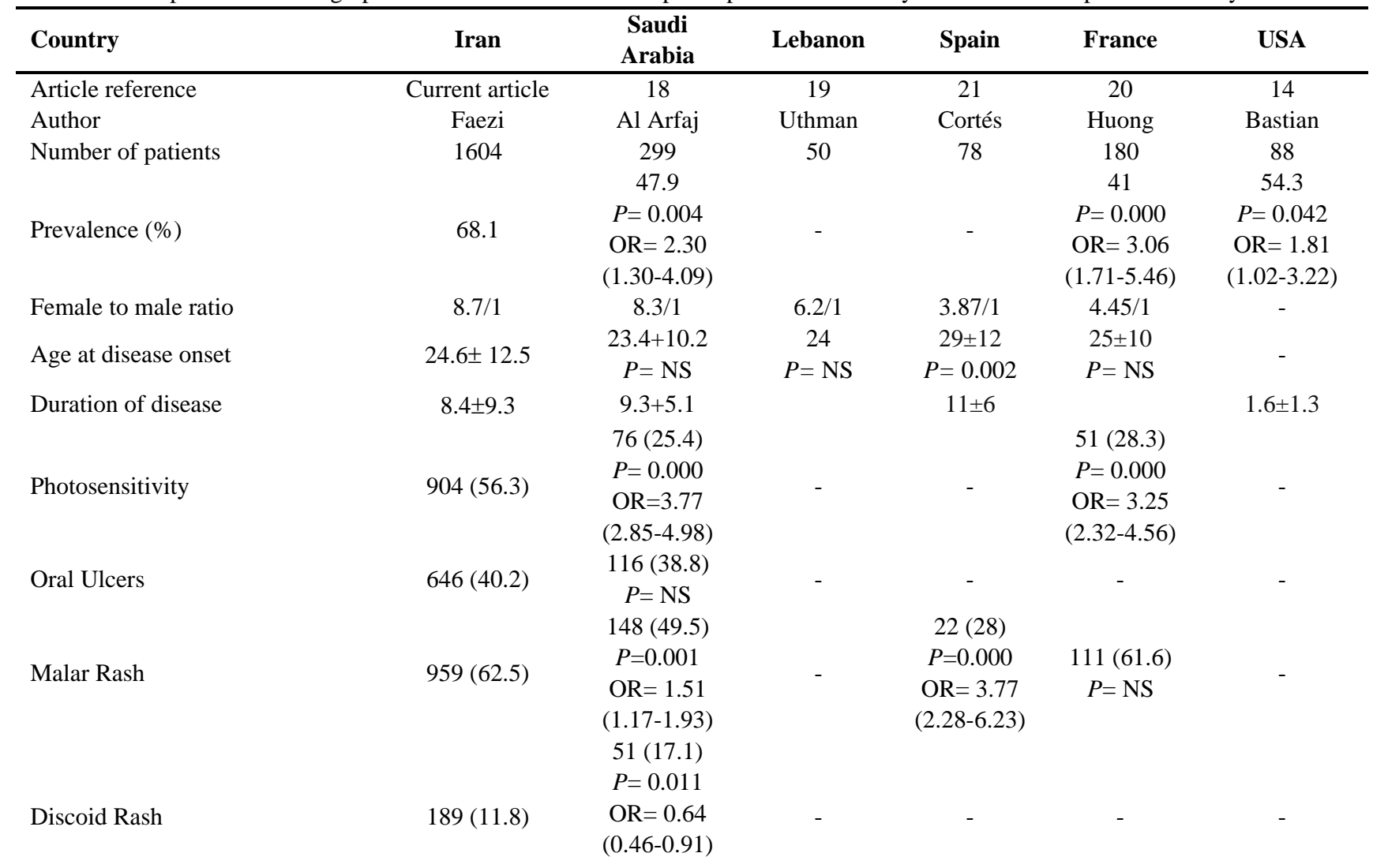


Lupus nephritis in patients with systemic lupus erythematosus

\begin{tabular}{|c|c|c|c|c|c|c|}
\hline Country & Iran & $\begin{array}{c}\text { Saudi } \\
\text { Arabia }\end{array}$ & Lebanon & Spain & France & USA \\
\hline Arthritis & $886(55.1)$ & $\begin{array}{c}208(69.6) \\
P=0.000 \\
\mathrm{OR}=0.53 \\
(0.41-0.70)\end{array}$ & $\begin{array}{c}50(100) \\
P=0.000 \\
\mathrm{OR}=0.2 \\
(0.00-0.17)\end{array}$ & $\begin{array}{c}24(31) \\
P=0.000 \\
\mathrm{OR}=2.76 \\
(1.69-4.51)\end{array}$ & $\begin{array}{c}153(85) \\
P=0.000 \\
\mathrm{OR}=0.22 \\
(0.14-0.33)\end{array}$ & - \\
\hline Pleuritis & 285 (18.6) & - & - & - & $\begin{array}{c}46(25.5) \\
P=0.000 \\
\mathrm{OR}=0.04 \\
(0.02-0.06)\end{array}$ & - \\
\hline $\begin{array}{l}\text { CNS } \\
\text { Involvement }\end{array}$ & $439(27.31)$ & - & $\begin{array}{l}9(18) \\
P=\mathrm{NS}\end{array}$ & $\begin{array}{c}7(9) \\
P=0.000 \\
\mathrm{OR}=3.81 \\
(1.74-8.35)\end{array}$ & $\begin{array}{c}39(21.6) \\
P=\mathrm{NS}\end{array}$ & $\begin{array}{c}7(8) \\
P=0.000 \\
\mathrm{OR}=4.35 \\
(1.99-9.49)\end{array}$ \\
\hline Hemolytic Anemia & $74(4.8)$ & $\begin{array}{c}229(76) \\
P=0.000 \\
\mathrm{OR}=0.01 \\
(0.01-0.02)\end{array}$ & - & $\begin{array}{c}1(1) \\
P=\mathrm{NS}\end{array}$ & $\begin{array}{c}111(61.6) \\
P=0.000 \\
\mathrm{OR}=0.03 \\
(0.02-0.04)\end{array}$ & - \\
\hline Leucopenia & $630(39.2)$ & $\begin{array}{c}79(26.4) \\
P=0.000 \\
\mathrm{OR}=1.79 \\
(1.36-2.37)\end{array}$ & - & $\begin{array}{l}26(33) \\
P=\mathrm{NS}\end{array}$ & $\begin{array}{c}90(50) \\
P=0.005 \\
\mathrm{OR}=0.64 \\
(0.47-0.88)\end{array}$ & $\begin{array}{l}33(37) \\
P=\text { NS }\end{array}$ \\
\hline Thrombocytopenia & $302(19.7)$ & $\begin{array}{c}35(11.7) \\
P=0.003 \\
\mathrm{OR}=1.20 \\
(1.20-2.54)\end{array}$ & - & $\begin{array}{l}10(13) \\
P=\mathrm{NS}\end{array}$ & $\begin{array}{c}55(30.5) \\
P=0.000 \\
\mathrm{OR}=0.53 \\
(0.37-0.74)\end{array}$ & $\begin{array}{c}15(17.1) \\
P=\mathrm{NS}\end{array}$ \\
\hline Hypertension & 464 (28.9) & $\begin{array}{c}137(45.8) \\
P=0.000 \\
\mathrm{OR}=0.47 \\
(0.37-0.61)\end{array}$ & - & - & $\begin{array}{c}6(3.3) \\
P=0.000 \\
\mathrm{OR}=11.59 \\
(5.10- \\
26.35)\end{array}$ & $\begin{array}{c}11(12) \\
P=0.001 \\
\mathrm{OR}=2.79 \\
(1.47-5.31)\end{array}$ \\
\hline ANA & $1239(80.7)$ & $\begin{array}{c}297(99.3) \\
P=0.000 \\
\mathrm{OR}=0.02 \\
(0.01-0.09)\end{array}$ & $\begin{array}{c}45(90) \\
P=0.033 \\
\mathrm{OR}=0.37 \\
(0.15-0.94)\end{array}$ & $\begin{array}{c}78(100 \%) \\
P=0.000 \\
\mathrm{OR}=0.04 \\
(0.01-0.31)\end{array}$ & $\begin{array}{c}169(93.8) \\
P=0.000 \\
\mathrm{OR}=0.22 \\
(0.12-0.41)\end{array}$ & $\begin{array}{c}84(95.2) \\
P=0.000 \\
\mathrm{OR}=0.16 \\
(0.06-0.44)\end{array}$ \\
\hline Anti-dsDNA & $1104(71.9)$ & $\begin{array}{c}244(81.6) \\
P=0.000 \\
\mathrm{OR}=0.49 \\
(0.36-0.68)\end{array}$ & $\begin{array}{c}40(80) \\
P=0.092 \\
\mathrm{OR}=0.55 \\
(0.27-1.11)\end{array}$ & $550 \pm 746$ & $\begin{array}{c}142(78.8) \\
P=0.005 \\
\mathrm{OR}=0.59 \\
(0.41-0.86)\end{array}$ & $\begin{array}{c}45(51.2) \\
P=0.001 \\
\mathrm{OR}=2.11 \\
(1.37-3.25)\end{array}$ \\
\hline
\end{tabular}

NS: non-significant

\section{Discussion}

Nephritis is a major cause of morbidity and mortality in SLE patients, specifically in developing countries [16]. The characteristics of LN patients have been described in several studies, but data relating to Middle Eastern countries has been scarcely reported. Iran is a country in the Middle East with a Caucasian majority population [3]. Therefore, it is a good candidate for the evaluation of the impact of genetic and environmental factors on different features of the disease.

This study identified a lupus nephritis prevalence rate significantly higher than that reported in a previous study $(48 \%)$ conducted in Fars province of Iran between 2001 and 2006 [17]. This comparison may be indicative of an alarming incremental pattern of nephritis in the Persian SLE population or of a more elaborate examination of patients in the current study.

Previous studies have emphasized malar rash, pericarditis, arterial hypertension, anemia, hypocomplementemia, and elevated anti-dsDNA values as the risk factors for the development of LN [8, 9, 10]. In the current study, manifestations of 1604 SLE patients with lupus nephritis were reported. The large sample size of this study allowed for a more accurate investigation of the associations of $\mathrm{LN}$ in comparison with past reports.

The characteristics of the current study population were compared with those of other major surveys from 
other regions in the Middle East, Europe, and North America [14, 18-21]. The overall prevalence rate of lupus nephritis was higher in the current study compared to notable surveys [22, 23]. It is noteworthy that previous studies have suggested that the highest rate of renal involvement in the world $(73 \%)$ was found in Indo-Asians [16, 24].

Moreover, the female-to-male $(\mathrm{f} / \mathrm{m})$ ratio in $\mathrm{LN}$ cases was higher in comparison with numerous previous studies. However, no significant difference in LN prevalence between the two genders was noted. According to a review article by Al Attia et al., nephritis is more prevalent in male SLE patients [25], while Flowers et al. [26] reported no difference between genders. The $\mathrm{f} / \mathrm{m}$ ratio in the current study may suggest an under-diagnosis of SLE among the male population.

Clinical and laboratory findings regarding photosensitivity, malar rash, CNS involvement, and ANA positivity were more prevalent among the current study population. Conversely, arthritis and hemolytic anemia were less frequently observed in LN cases of this study. This discordance may be due in part to the sample size and inclusion criteria of various studies. However, this notion may stress the role of geographic and ethnical variations on genetic and environmental factors. It can show the combinative role of environmental factors and genetic factors on $\mathrm{LN}$ presentation in patients of the current study.

The mean age at SLE onset in this study was comparable to numerous other reports [14, 18-20]. Class IV was the most common type of $\mathrm{LN}$ in this study, similar to reports from North America, Europe, and other countries in the Middle East [18-20, 27]. In contrast a number of surveys have reported class III type of nephritis as most prevalent in SLE patients [28, 29]. This controversial result can be due to the low number of biopsies conducted in these studies.

The comparison of LN and non-LN subgroups in the current study revealed that the involvement of major organs, including the central nervous system, hematologic, cardiopulmonary, and musculoskeletal involvements were more common in LN patients.

The comparison of the clinical picture of LN and non-LN subsets of SLE patients was performed in some previous surveys. Ayana et al. reported that pleuritis, hemolytic anemia, and hypertension were more prevalent in $\mathrm{LN}$ patients [30]. In a study by Huong et al., malar rash, psychosis, myocarditis, pericarditis, lymphadenopathy, and hypertension were more prevalent in patients with renal involvement [20].
In Asian SLE cases, hypertension, thrombocytopenia, and leucopenia were found to be predictors of nephritis [31]. The association between hypertension and endstage renal disease was reported in some other studies $[32,33]$. In accordance with the current results, Pristiner et al. described LN patients as having an increased frequency of central nervous system involvement, anemia, thrombocytopenia, and low complement levels [34]. Other studies have reported psychosis, pericarditis, alopecia, and articular complications were more common in the LN subset $[35,36]$.

According to the current results, discoid rash was significantly more common in the non-LN subset of this study. This result is in agreement with a number of previous studies [30, 37]. Nonetheless, some opposing results have been seen in a study of an Arab population which reported a positive association between discoid rash and $\mathrm{LN}$ development $[25,38]$. These contradictory results may be due to the small sample size in some of the surveys, the variable duration of follow-up in different series, and the roles of genetics and environment on manifestations of disease as the current study was conducted in Iran and all studied cases investigated patients of Persian ethnicity.

The prevalence rates of positive FANA, raised antidsDNA, and hypocomplementemia were significantly higher in LN patients in the current study. These laboratory findings were in accordance with a number of previous studies [1, 20, 39-43]. Moreover, neuropsychiatric manifestations were more common in the LN subset, psychosis, peripheral neuropathy, and convulsions were significantly more common in the LN subset.

Although the number of subjects in the current study was substantial, its unicenter nature may be a limiting factor for this study. Furthermore, the authors did not have access to all renal biopsies. It is noteworthy that the center is the major referral center for SLE diagnosis and management in the country. Moreover, the current survey covered different ethnicities in Iran; however, the dataset did not discriminate among ethnicities. The diversion can be addressed in future studies.

\section{Conclusion}

This study showed that $\mathrm{LN}$ is associated with more extrarenal manifestations other than discoid rash that had a negative association with LN. Moreover, the results revealed that type IV nephritis was the most common type of lupus nephritis. The results suggest a 
Lupus nephritis in patients with systemic lupus erythematosus

more elaborate renal work-up, specifically in the male SLE population, in order to prevent long-term sequels.

\section{Conflicts of interest}

The authors declare no conflicts of interest.

\section{Acknowledgments}

The authors would like to thank the patients who confided in them.

\section{References}

1. Cervera R, Khamashta MA, Font J, Sebastiani GD, Gil A, Lavilla P, et al. Systemic lupus erythematosus: clinical and immunologic patterns of disease expression in a cohort of 1,000 patients. The European Working Party on Systemic Lupus Erythematosus. Medicine 1993; 72(2): 113-24. doi: 10.1097/ 00005792-199303000-00005.

2. Lee H, Bae S. Recent advances in systemic lupus erythematosus genetics in an Asian population. Inter J of Rheum Diseases 2014; 18(2): 192-199. doi: 10.1111/ 1756-185x.12498.

3. Mok CC, Lau CS. Pathogenesis of systemic lupus erythematosus. $\boldsymbol{J}$ of Clinical Pathology 2003; 56(7): 481-90. doi: 10.1136/jcp.56.7.481.

4. Danchenko N, Satia JA, Anthony MS. Epidemiology of systemic lupus erythematosus: a comparison of worldwide disease burden. Lupus 2006; 15(5): 308-18. doi 10.1191/0961203306lu2305xx.

5. Davatchi F, Jamshidi AR, Banihashemi AT, Gholami J, Forouzanfar MH, Akhlaghi M, et al. WHO-ILAR COPCORD Study (Stage 1, Urban Study) in Iran. $\boldsymbol{J}$ of Rheum 2008; 35(7): 1384.

6. Seligman VA, Lum RF, Olson JL, Li H, Criswell LA. Demographic differences in the development of lupus nephritis: a retrospective analysis. The American J of Med 2002; 112(9): 726-9. doi: 10.1016/ s0002-9343(02)01118-x.

7. Cameron JS. Lupus nephritis. $\boldsymbol{J}$ of the American Society of Nephrology 1999; 10(2): 413-24.

8. Galindo-Izquierdo M, RodriguezAlmaraz E, Pego-Reigosa JM, Lopez-Longo FJ, Calvo-Alen J, Olive A, et al. Characterization of Patients With Lupus Nephritis Included in a Large Cohort From the Spanish Society of Rheumatology Registry of Patients With Systemic Lupus Erythematosus (RELESSER). Medicine 2016; 95(9):e2891.

9. Maroz N, Segal MS. Lupus nephritis and end-stage kidney disease. The American $J$ of the Med Sciences 2013; 346(4): 319 23. doi: $10.1097 /$ maj.0b013e31827 f4ee3.

10. Burling $\mathrm{F}, \mathrm{Ng} \mathrm{J}$, Thein $\mathrm{H}$, Ly $\mathrm{J}$, Marshall MR, Gow P. Ethnic, clinical and immunological factors in systemic lupus erythematosus and the development of lupus nephritis: results from a multiethnic New Zealand cohort. Lupus 2007; 16(10): 830-7. doi: 10.1177/ 0961203307080225.

11. Ortega LM, Schultz DR, Lenz O, Pardo V, Contreras GN. Review: Lupus nephritis: pathologic features, epidemiology and a guide to therapeutic decisions. Lupus 2010; 19(5): 557-74. doi: 10.1177/ 0961203309358187.

12. Perkowska-Ptasinska A, DeborskaMaterkowska D, Bartczak A, Stompor T, Liberek T, BulloPiontecka B, et al. Kidney disease in the elderly: biopsy based data from 14 renal centers in Poland. BMC nephrology 2016; 17(1): 194. doi: 10.1186/s12882-0160410-8.

13. Okpechi IG, Swanepoel CR, Tiffin N, Duffield M, Rayner BL. Clinicopathological insights into lupus nephritis in South Africans: a study of 251 patients. Lupus 2012; 21(9): 1017-24. doi: 10.1177/0961203312441981.

14. Bastian HM, Roseman JM McGwin G, Jr., Alarcon GS, Friedman AW, Fessler BJ, et al. Systemic lupus erythematosus in three ethnic groups. XII. Risk factors for lupus nephritis after diagnosis. Lupus 2002; 11(3): 152-60. doi: 10.1191/0961203302 lu158oa.

15. Churg J, Sobin L. Renal disease: classification and atlas of glomerular diseases Igaku-Shoin. Tokyo, New York, 1982.

16. Tikly M, Navarra SV. Lupus in the developing world--is it any different? Best Pract Res Clin Rheumatol 2008; 22(4): 643-55. doi: 10.1016/j.berh.2008.05.003.

17. Nazarinia MA, Ghaffarpasand F, Shamsdin A, Karimi AA, Abbasi $\mathrm{N}$, Amiri A. Systemic lupus erythematosus in the Fars Province of Iran. Lupus 2008; 17(3): 221-7. doi: 10.1177/0961203307086509.

18. Al Arfaj AS, Khalil N, Al Saleh S. Lupus nephritis among 624 cases of systemic lupus erythematosus in Riyadh, Saudi Arabia. Rheumatol Int 2009; 29(9): 1057-67. doi: 10.1007/s00296-009-0905-8

19. Uthman IW, Muffarij AA, Mudawar WA, Nasr FW, Masri AF. Lupus nephritis in Lebanon. Lupus 2001; 10(5): 378-81. doi: 10.1191/096120301670808045.

20. Huong DL, Papo T, Beaufils H, Wechsler B, Bletry O, Baumelou $A$, et al. Renal involvement in systemic lupus erythematosus. A study of 180 patients from a single center. Medicine 1999; 78(3): 14866. doi: 10.1097/00005792199905000-00002.

21. Cortes-Hernandez J, Ordi-Ros J, Labrador M, Bujan S, Balada E, Segarra A, et al. Antihistone and anti-double-stranded deoxyribonucleic acid antibodies are associated with renal disease in systemic lupus erythematosus. The American J of Med 2004; 116(3): 165-73. doi: 10.1016/j.amjmed. 2003.08.034.

22. Cervera R, Khamashta MA, Font J, Sebastiani GD, Gil A, Lavilla P, et al. Morbidity and mortality in systemic lupus erythematosus during a 10-year period: a comparison of early and late manifestations in a cohort of 1,000 patients. Medicine 2003; 82(5): 299-308. doi: 10.1097/01.md. 0000091181.93122 .55

23. Cervera R, Khamashta MA, Hughes GR. The Euro-lupus project: epidemiology of systemic lupus erythematosus in Europe. Lupus 2009; 18(10): 869-74. doi: $10.1177 / 0961203309106831$.

24. Malaviya AN, Chandrasekaran AN, Kumar A, Shamar PN. 
Systemic lupus erythematosus in India. Lupus 1997; 6(9): 690-700. doi:

10.1177/096120339700600903.

25. Al Attia HM. Lupus Nephritis among Arabs- Differences with other Races; Emphasis on Clinicopathological and Serological Perspectives. Saudi J Kidney Dis Transpl 2000; 11(3): 370-80.

26. Flower C, Hennis A, Hambleton IR, Nicholson G. Lupus nephritis in an Afro-Caribbean population: renal indices and clinical outcomes. Lupus 2006; 15(10): 689-94. doi: 10.1177/0961203306072415.

27. Neumann K, Wallace DJ, Azen C, Nessim S, Fichman M, Metzger AL, et al. Lupus in the 1980s: III. Influence of clinical variables, biopsy, and treatment on the outcome in 150 patients with lupus nephritis seen at a single center. Seminars in Arthritis and Rheumatism 1995; 25(1): 47-55 doi: $\quad 10.1016 / \mathrm{s} 0049-0172(95)$ 80017-4.

28. Al Attia HM, Al Ahmed YH, Chandani AU. Serological markers in Arabs with lupus nephritis. Lupus 1998; 7(3): 198-201. doi: 10.1191/096120398678920000.

29. Al-Jarallah K, Al-Awadi A, Siddiqui H, Al-Salim I, Shehab D, Umamaheswaran I, et al. Systemic lupus erythematosus in Kuwaithospital based study. Lupus 1998; 7(7): 434-8. doi: 10.1191/ 096120398678920389

30. Anaya JM, Canas C, Mantilla RD, Pineda-Tamayo R, Tobon GJ, Herrera-Diaz C, et al. Lupus nephritis in Colombians: contrasts and comparisons with other populations. Clin Rev Allergy Immunol 2011; 40(3): 199-207. doi: 10.1007/s12016-010-8249-4.

31. Thumboo J, Fong KY, Chia HP, Chng HH, Koh ET, Leong KH, et al. Clinical predictors of nephritis in systemic lupus erythematosus. Ann Acad Med Singapore 1998; 27(1): 16-20.

32. Naiker IP, Chrystal V, Randeree IG, Seedat YK. The significance of arterial hypertension at the onset of clinical lupus nephritis. Postgrad Med J 1997; 73(858): 230-3. doi: 10.1136/pgmj.73.858.230.

33. Font J, Ramos-Casals M, Cervera R, Garcia-Carrasco M, Torras A, Siso A, et al. Cardiovascular risk factors and the long-term outcome of lupus nephritis. QJM 2001; 94(1): 19-26. doi: 10.1093/qjmed/ 94.1.19.

34. Pistiner M, Wallace DJ, Nessim S, Metzger AL, Klinenberg JR. Lupus erythematosus in the 1980s: a survey of 570 patients. Semin Arthritis Rheum 1991; 21(1): 5564. doi: 10.1016/0049-0172(91) 90057-7.

35. Skare TL, Schonrock AC. Clinical profile of patients with lupus nephritis. Reumatismo 2009; 61(4): 316-7.

36. Walker RJ, Bailey RR, Swainson CP, Lynn KL. Lupus nephritis: a 13-year experience. $\boldsymbol{N} \mathbf{Z} \mathbf{M e d} \mathbf{J}$ 1986; 99(814): 894-6.

37. Watson R. Cutaneous lesions in systemic lupus erythematosus. Med Clin North Am 1989; 73(5): 1091-111. doi: 10.1016/s00257125(16)30621-6.

38. Al Arfaj AS, Khalil N, Al Saleh S. Lupus nephritis among 624 cases of systemic lupus erythematosus in Riyadh, Saudi Arabia.
Rheumatology International 2009; 29(9): 1057-67. doi: 10.1007/s00296-009-0905-8.

39. Anaya JM, Uribe M, Perez A Sanchez JF, Pinto LF, Molina JF, et al. Clinical and immunological factors associated with lupus nephritis in patients from northwestern Colombia. Biomedica 2003; 23(3): 293-300. doi: $\quad 10.7705 /$ biomedica.v23i3. 1223.

40. Duzgun N, Hoier-Madsen M, Wiik A, Tokgoz G. The frequency of autoantibodies in Turkish patients with lupus nephritis. Rheumatol Int 1997; 17(1): 1-4. doi: 10.1007/pl00006844.

41. Garcia CO, Molina JF, GutierrezUrena S, Scopelitis E, Wilson WA, Gharavi AE, et al. Autoantibody profile in African-American patients with lupus nephritis. Lupus 1996; 5(6): 602-5. doi: 10.1177/0961203396005608.

42. Kramers C, Termaat RM, ter Borg EJ, van Bruggen MC, Kallenberg CG, Berden JH. Higher antiheparan sulphate reactivity during systemic lupus erythematosus (SLE) disease exacerbations with renal manifestations; a long term prospective analysis. Clin Exp Immunol 1993; 93(1): 34-8.

43. Ravirajan CT, Rowse L, MacGowan JR, Isenberg DA. An analysis of clinical disease activity and nephritis-associated serum autoantibody profiles in patients with systemic lupus erythematosus: a cross-sectional study. Rheumatology (Oxford) 2001; 40(12): 1405-12. doi: 10.1093/rheumatology/40.12.1405. 